\title{
Oligodendrocyte Fate Determination in Human Embryonic Stem Cells
}

\author{
Siddharth Gupta ${ }^{1}$, Angelo All1,4 and Candace Kerr ${ }^{2,3}$ \\ ${ }^{1}$ Department of Biomedical Engineering \\ 2Department of Obstetrics and Gynecology \\ Institute for Cell Engineering \\ ${ }^{4}$ Department of Neurology \\ Johns Hopkins University School of Medicine, Baltimore, MD \\ United States of America
}

\section{Introduction}

Oligodendrocytes (OL) are cells of the glial lineage which play a critical role in the central nervous system (CNS) by producing the multilamellar protein, myelin. Oligodendrocytes extend processes which wrap around the axons of several neurons. This myelin sheath increases neuronal conduction by decreasing ion leakage and capacitance of the axonal membrane and increasing saltatory conduction. Damage to oligodendrocytes results in loss of myelin and consequent functional impairment due to loss or decay of neuronal conduction. Demyelination in the CNS is the hallmark of conditions such as spinal cord injury (SCI), transverse myelitis and multiple sclerosis - resulting in functional impairment across the sensory, motor and cognitive domains. Current research on treatment of SCI focuses on the implantation of oligodendrocyte progenitor cells (OPC) into the injured region to achieve remyelination of the spared axons and potentially repair the sensory and motor pathways. However, this approach requires a large and relatively pure population of OPCs, which are differentiated from other multipotent cell lineages. Human embryonic stem cells have been used in several studies for this purpose and hence, it is important to understand the molecular mechanisms regulating the differentiation of pluripotent hESCs to oligodendrocytes. Elucidation of such mechanisms may lead to the development of more efficient differentiation protocols and the derivation of cells with improved myelination potential for implantation in injured spinal cords.

While the molecular basis for hESC differentiation into OL lineage cells is not completely understood, several recent studies have filled some of the gaps in our knowledge of the field. The journey from a pluripotent state to commitment to the OL fate is characterized by a complex interplay between genetic regulation and epigenetic modifiers such as histone modification, DNA methylation and microRNAs (miRNAs). Global miRNA expression profiling of OL differentiation from hESCs has revealed that a significant number of the differentially expressed miRNAs have targets hypothesized to be involved in myelination and OL development. Such studies are complemented by histone modification analyses in ESCs which show that specific histone acetyltransferases (HATs) and histone deacetylases (HDACs) are up- or down-regulated during different time points in OL differentiation to 
guide myelin production. This review focuses on the role of miRNAs in oligodendrocyte development from human embryonic stem cells and elucidates a new protocol developed to obtain oligodendrocytes from human embryonic stem cells with high yield and purity.

\section{MicroRNA regulation of oligodendrocyte development}

To date, many studies have attempted to unravel mechanisms of stem cell fate determination by studying gene expression by measuring messenger RNA (mRNA) expression. However, in the early-mid 90's a novel class of RNA molecules was discovered that regulated gene expression at the level of translation in C. elegans. These RNAs were shown to regulate the translation of a target mRNA, by directly base-pairing to its 3'untranslated region (3' UTR) (Lee, Feinbaum \& Ambros 1993, Wightman, Ha \& Ruvkun 1993). Nevertheless, the broad significance of these small RNAs was not fully appreciated until only a few years ago when many similar molecules were further identified in $C$. elegans, Drosophila, and in some mammals (Lee, Ambros 2001, Lagos-Quintana et al. 2001), and these newly recognized regulatory RNAs were termed microRNAs (miRNAs or miRs). To date, sequencing libraries of cloned small RNAs and bioinformatic analyses of genomic sequences have led to the identification of $\sim 500$ verified mammalian miRNAs while studies exploiting the high degree of conservation of miRNAs across mammalian genomes have suggested that as many as 1000 human miRNAs are likely to exist (Berezikov et al. 2005, Bentwich et al. 2005). Despite these great advances in the identification of miRNAs, our understanding of their roles in cellular processes remains at a very early stage although there is evidence suggesting that miRNA dysfunction contributes significantly to oncogenesis and stem cell self-renewal.

MiRNAs are found in plants, viruses and animals and are generated via a multi-stage process. In mammals they are first transcribed as long precursor transcripts $(\sim 60-80$ nucleotides) known as primary (pri)-miRNAs containing a hairpin loop (Lee et al. 2002). PrimiRNAs are then processed into shorter hairpin shaped precursors (pre)-miRNAs in the nucleus and transported to the cytoplasm. There, the RNase-III enzyme Dicer performs a second cleavage to generate a double-stranded 21-23 nucleotide RNA molecule (Bernstein et al. 2001, Grishok et al. 2001, Hutvágner et al. 2001, Ketting et al. 2001, Knight, and Bass 2001). A large protein complex known as the RNA-induced silencing complex, or RISC, associates with this RNA duplex and unwinds it. Generally, only one strand is stably incorporated into RISC while the other is discarded and rapidly degraded (Meister et al. 2004). After the RISC is formed the miRNAs guide it to the target mRNA that is subsequently cleaved or translationally silenced. The degree of complementarity between a miRNA and its target dictates the mechanism of silencing (Meister et al. 2004, Hutvágner et al. 2004, Brennecke et al. 2003)

While degradation occurs predominantly in plants, in mammals the predominant mechanism appears to be through imperfect base-pairing between a miRNA and its target, resulting in translational silencing through a complex mechanism that appears to involve inhibition of both translation initiation and elongation (Pillai, Bhattacharyya \& Filipowicz 2007).

MiRNAs are attractive candidates for regulating stem cell identity, which includes selfrenewal and cell fate decisions, as their ability to simultaneously regulate many targets provides a means for coordinated control of gene action (Chen et al. 2007). Although direct functional roles in stem cell biology are just emerging, corroborating evidence from 
expression patterns, predicted targets, and from overexpression studies suggests miRNAs are key regulators (Cheng et al. 2005). For example, the loss of Dicer1 in mice has been demonstrated to cause embryonic lethality as well as loss of stem cell populations implicating a role for miRNAs in stem cell self-renewal (Bernstein et al. 2003, Murchison et al. 2005). Based on several reports from mouse and human studies, distinct sets of miRNAs are expressed specifically in pluripotent stem cells and not in adult tissues further implicating their role in stem cell self-renewal. In addition, Argonaute family proteins, which are key components of the RISC complex, have also been shown to be required in the maintenance of germline stem cells in different organisms (Carmell et al. 2002).

The role of miRNAs in oligodendrocyte fate determination has been a recent field of research and a few studies have reviewed the state of the current knowledge on the subject (He et al. 2011, Emery 2010, Dugas, Notterpek 2011).. This chapter aims to review the advances made in understanding oligodendrocyte fate determination by miRNAs and elucidate a novel protocol to derive OLs from embryonic stem cells in vitro to study their development.

\subsection{MicroRNAs in glial fate determination}

Zheng et al first reported that miRNAs were essential for the "developmental switch from neurogenesis to gliogenesis" (Zheng et al. 2010). The authors deleted Dicer, a protein necessary for functional miRNA synthesis, in the mouse ventral spinal neuroepithelium, where embryonic gliogenesis occurs. Neural patterning and motor neuron development occurred even in the absence of miRNA formation, showing that they are probably not involved in neuron maturation. However, oligodendrogenesis in the ventral spinal cord was blocked in the absence of Dicer, as confirmed by the complete absence of PDGFRa+ cells and a huge reduction in Sox10+ cells in the spinal cord parenchyma of Dicer mutants. On similar lines, astrogliogenesis was also found to be miRNA-dependent, as the study found that Dicer deletion led to the complete block of the development of a subset of astrocytes from the ventral neuroepithelium. This was confirmed by the lack of GFAP immunostaining of a small region flanking the floor plate when compared to the control. However, this study did not implicate any specific miRNA species as being involved in the regulation of gliogenesis in the developing spinal cord.

\subsection{MicroRNAs in oligodendrocyte development}

A 2009 study by Shin et al definitively established that miRNAs were involved in epigenetic regulation of oligodendrocyte function. This was performed by the OL-specific knockout of Dicer in postnatal mice. The Dicer protein is essential for synthesis of functional miRNAs and it was found that its elimination in postnatal OLs led to demyelination, oxidative damage, inflammatory astrocytosis and microgliosis in the brain. This phenotype resulted primarily from the disruption of miR-217 and consequent upregulation of its target ELOVL7 (elongation of very long chain fatty acids protein 7). Overexpression of ELOVL7 leads to lipid accumulation in the myelin rich regions of the brain and significant decrease in peroxisomal $\beta$-oxidation activity (Shin et al. 2009).

In the first study to analyze the global miRNA expression pattern in oligodendrocytes, Lau et al identified 98 miRNAs expressed by developing oligodendrocytes in the postnatal rat brain and found that 37 of these have an mRNA bias (Lau et al. 2008). In addition, the predicted protein targets of 13 miRNAs were dynamically regulated during OL 
development. In particular, the study identified miR-9 as a candidate miRNA with an important regulatory role during the transition from $\mathrm{OPC}(\mathrm{A} 2 \mathrm{~B} 5+/ \mathrm{GalC}-)$ to premyelinating $\mathrm{OL}(\mathrm{A} 2 \mathrm{~B} 5+/ \mathrm{GalC}+)$ and it was found that miR-9 downregulated the expression of the peripheral myelin protein (PMP) 22. PMP22 is expressed by Schwann cells and is a component of the compact myelin of the peripheral nervous system. Interestingly, miR-9 is not expressed by Schwann cells.

Another study identified miR-23 and its target, Lamin B1 (LMNB1) as a regulatory component of OL differentiation (Lin, Fu 2009). Genomic duplication of LMNB1 has been implicated in autosomal dominant leukodystrophy (Padiath et al. 2006), a disease characterized by severe myelin loss in the CNS. Nuclear lamins such as LMNB1 interact with heterochromatin to regulate DNA synthesis and transcription and LMNB1 specifically regulates OL function; this was confirmed by the repression of transcription of OL-specific genes such as myelin basic protein (MBP), proteolipid protein (PLP) and myelin oligodendrocyte glycoprotein (MOG) by overexpression of LMNB1. The Lin et al study showed that miR-23 downregulates LMNB1 in normal OLs and that downregulation of LMNB1 by miR-23 was important for the development of OLs from glial cell cultures (Lin, Fu 2009). The effect of LMNB1 on differentiation was confirmed by the observation that increased LMNB1 gene dosage caused an arrest in differentiation and led to the development of an MBP and PLP negative phenotype. This was hypothesized to be due to either faulty transcription of these genes or defective nuclear export.

A 2010 study by Zhao et al identified miR-219 and miR-338 as OL-specific miRNAs. This was confirmed by the complete absence of these two miRNAs in the spinal cord of Olig1 mutant mice. Fluorescent in situ hybridization revealed that miR-219 and miR-338 positive cells were found only in the white matter of the spinal cord, which is where OLs reside. Further, it was found that these two miRNAs promoted OPC maturation in vitro and in vivo. Transfection of OPC-enriched cultures with these miRNAs led to a significant increase in the number of MBP+ cells (a marker of mature OLs) and a slight decrease in the number of PDGFRa+ OPCs. MiR219 and miR-338 were also found to be necessary for OL maturation. The study also identified Sox 6 and Hes 5 as potential protein targets of these miRNAs. These two transcription factors are inhibitors of OL maturation and have been shown to downregulate myelin gene expression and oligodendrocyte maturation (Kondo, Raff 2000, Liu et al. 2006). Sox6 and Hes5 are downregulated by miR-219 and miR-338. The authors suggest that commitment to the oligodendroglial lineage would require downregulation of transcription factors which induce differentiation to other neural cell fates and this was confirmed by the observation that miR219 and miR-338 also downregulated other proneurogenic transcription factors such as NeuroD1, Is11 and Otx2. In summary, these two miRs promote OL maturation by simultaneously inhibiting the inhibitors of OL differentiation and transcription factors which promote differentiation to non-OL neural cell fates.

Another recent study confirmed the importance of miR-219 and miR-338 in OL differentiation and maturation (Dugas et al. 2010). In addition, it also found miR-138 to be strongly upregulated during OL differentiation. Among the three, miR-219 was found to be the strongest inducer of OL differentiation and its transfection in a purified OPC population increased the number of differentiated OLs expressing both early (CNP, MBP) and late (MOG) OL markers. OLs induced by transfection with miR-138 only expressed early OL markers. As expected, OL-specific miRNAs were found to target genes that are repressed during OL differentiation. In addition, this study also found that miR-219 downregulates inhibitors of OL differentiation. The validated targets of miR-219 were found to include 
PDGFRa, Sox6, FoxJ3 and ZFP238. PDGF has been known to be an OPC mitogen for multiple decades (Besnard et al. 1987). ZFP238 and FoxJ3 had previously not been functionally characterized in OPCs and this study confirmed that FoxJ3 and ZFP238 are inhibitors of OL differentiation by constitutively expressing these genes in OPCs and observing significantly reduced differentiation to the mature OL stage.

A study by Letzen et al was the first to perform a global miRNA analysis of cells isolated from 8 developmental stages from the pluripotent embryonic stem cell state to a mature, myelinating OL state (Letzen et al. 2010). Significantly, this study analyzed the expression of miRNAs in human cells as opposed to rodent models used in prior investigations. The study detected 183 miRNAs over the eight stages of oligodendrocyte maturation and also identified the highest differentially expressed miRNAs at each transition in the pluripotentto-mature OL differentiation scheme. These differentially-expressed miRNAs were then matched to potential protein targets which revealed proteins such as chromosome 11 open reading frame 9 (C11orf9), claudin-11 (Cldn11), myelin transcription factor 1-like (Myt11), myelin-associated oligodendrocyte basic protein (Mobp), myelin protein zero-like 2 (Mpzl2), and discoidin domain receptor tyrosine kinase 1 (Ddr1). The study focused on two miRNAs - miR-199a-5p and miR145, both of which show a decreasing expression level during the early to mid OP transition. C11orf9, which appears to be the human analog of the mouse myelin regulatory factor (MRF) was the target protein predicted for these 2 miRNAs. MRF has been shown to be necessary for myelination and OL maturation (Emery et al. 2009). It is thought that the decrease in miR199a-5p levels during OPC maturation may be parallel to the observed increase in MRF expression during the same time window, implying that miR-199a-5p may be one of the regulators of myelination and OPC maturation. MiR-214 was also observed to be strongly downregulated during the early-tomid OPC transition and its predicted target is myelin-associated oligodendrocyte basic protein $(\mathrm{MOBP})$, an important structural component of myelin.

\subsection{Oligodendrocytes, miRNA and disease}

Dysfunctional oligodendrocytes due to misregulation by miRNAs have recently been implicated in diseases of the central nervous system. For instance, mutations in several miRNAs have been discovered in the pathogenesis of multiple sclerosis (MS) (Junker, Hohlfeld \& Meinl 2010). Specifically, miR-219 and miR-338 showed the maximum relative reduction in expression when the entire microRNAome of healthy, mature OLs was compared with chronic, inactivated MS tissue lesions (Junker et al. 2009). Other reports have also shown that miRNAs provide a mechanism for resistance against viral infection, and that miR-122 levels were significantly reduced in OLs infected with the Borna disease virus. This is significant as the Borna disease virus causes neurological disease in animals, and recent findings have implicated that it may also play a role in some human neurological and psychiatric conditions including bipolar disorder and depression (VandeWoude et al. 1990). In this case, overexpression of miR-122 inhibited viral protein synthesis and viral gene transcription and translation (Qian et al. 2010).

In one study to examine the possible role of miRNAs in the development of schizophrenia, the expression levels of 435 miRNAs in postmortem brain samples of schizophrenic patients were compared with those of psychiatric healthy controls (Moreau et al. 2011). In this study, $19 \%$ of the miRNAs analyzed showed misexpression in the schizophrenic samples, with these miRNAs mostly being downregulated compared to the healthy controls. On the other hand, a previous study identified differential expression of 28 miRNAs in the postmortem 
dorsolateral prefrontal cortex (Brodmanns Area) of schizophrenic individuals (Santarelli et al. 2011). $89 \%$ of these 28 miRNAs were upregulated and quantitative PCR was used to validate this finding for miR-328, miR-17-5p, miR-134, miR-652, miR-382, and miR-107. This elevation was linked to the observed upregulation of Dicer activity in these samples. The role of miRNAs in other neurological disorders has been reviewed $(\mathrm{Xu}$, Karayiorgou \& Gogos 2010).

\section{Methods of oligodendrocyte differentiation}

Unlike animal models, the study of oligodendrocyte development in humans has been generally limited in scope by the lack of models both in vivo and vitro that can be utilized to study this process. However, human embryonic stem cells provide an exciting model to help identify mechanisms that regulate the differentiation of oligodendrocytes. This includes elucidating the role of miRNAs in regulating the oligodendrocyte fate. This section describes a novel protocol for generating oligodendrocyte fated cells from human embryonic stem cells which have been developed in part from several published protocols (Nistor et al. 2005, Kerr et al. 2010).

\subsection{Materials}

\subsubsection{Buffers and solutions}

PBS: Phosphate buffered saline, without $\mathrm{Ca}^{+2}$ and $\mathrm{Mg}^{+2}$, $\mathrm{pH} 7.0$ (Invitrogen).

Trypsin/EDTA: HBSS containing $0.05 \%$ trypsin and 0.53 mM EDTA (Sigma).

Collagenase: $1 \mathrm{mg} / \mathrm{ml}$ collagenase IV (Invitrogen) in PBS, filtered.

\subsubsection{Culture media}

Basic culture medium for MEF: (Mouse embryonic fibroblast line PMEF-CF1 from Millipore): DMEM high glucose, supplemented with 10\% Fetal Bovine Serum (Invitrogen), 2 $\mathrm{mM}$ glutamax (Invitrogen), $5 \mathrm{U} / \mathrm{ml}$ penicillin-streptomycin (Invitrogen), and $0.1 \mathrm{mM}$ nonessential amino acids (NEAA).

Basic culture medium for undifferentiated human embryonic stem cells: DMEM/F12 (Invitrogen), supplemented with 20\% Knockout Serum Replacement (Invitrogen), $2 \mathrm{mM}$ glutamax (Invitrogen), $5 \mathrm{U} / \mathrm{ml}$ penicillin-streptomycin (Invitrogen), $0.1 \mathrm{mM}$ non-essential amino acids and $3.5 \mu 1 \beta$-mercaptoethanol supplemented with basic fibroblast growth factor (FGF2).

Basic culture medium for neural and oligodendrocyte progenitors: Neural Basal Media, supplemented with 10\% Bovine Serum Albumin in PBS, filtered (Gibco), 0.5\% N2 supplement (Invitrogen), $0.1 \mathrm{mM} \beta$-mercaptoethanol (Sigma) and $25 \mathrm{ug} / \mathrm{ml}$ gentamicin (Invitrogen).

\subsubsection{Fixatives}

4\% Paraformaldehyde: 4g paraformaldehyde in $100 \mathrm{ml}$ PBS. To dissolve the paraformaldehyde, the PBS was preheated at $90^{\circ} \mathrm{C}$ and sodium hydroxide $(\mathrm{NaOH})$ added drop-wise slowly until the solution turns clear. The solution was cooled down before use.

\subsection{Cell culture}

Human ESCs were maintained on irradiated mouse embryonic fibroblasts (MEFs) in ESC growth media. Prior to differentiation, ESCs were separated from the feeder layer using a 
solution of $1 \mathrm{mg} / \mathrm{ml}$ collagenase and plated on a $4 \%$ matrigel (BD Biosciences) substrate for 5 to 7 days and fed feeder-conditioned media daily. Cells were subsequently differentiated into embryoid bodies (EBs), neural progenitors (NPC), glial restricted precursors (GPC), and oligodendrocyte precursors (OPC) and finally mature oligodendrocytes (OL).

\subsubsection{Preparation of MEF feeder layers}

MEFs were maintained in basic MEF culture medium. The feeder cells were prepared the day before ESCs are expanded. The MEFs were plated at a density of $10 \times 10^{4}$ cells $/ \mathrm{cm}^{2}$ onto $0.1 \% \mathrm{w} / \mathrm{v}$ gelatin (Stem Cell Technologies) -coated culture dishes. Next morning, the feeder plates were $\gamma$-irradiated with a dose of $50 \mathrm{~Gy}$ (5000 rads) to induce cell cycle arrest. After irradiation, the culture medium was replaced. MEFs can also be mitotically-inactivated by treatment with mitomycin C (Sigma) at a concentration of $10 \mu \mathrm{g} / \mathrm{ml}$ for 4 hours at $37^{\circ} \mathrm{C}$. The ESCs were plated on top of the MEF feeder layer using collagenase as described below. The medium was replaced daily with fresh medium supplemented with growth factors.

\subsubsection{Human embryonic stem cells}

The derivation and maintenance of human embryonic stem cells has been covered at length and details can be found in the following reviews (Park et al. 2003, Draper et al. 2004, Lu et al. 2006, Suemori et al. 2006, Ludwig et al. 2006, Hoffman, and Carpenter 2005). In brief, a culture plate with mitotically inactivated MEF feeder cells was prepared $24 \mathrm{~h}$ before use with ESCs with MEF basic culture media. The medium was removed from a culture dish of ESCs and the dish was washed with PBS. ESC can be expanded using either collagenase or trypsin. In both cases, however, over trypsinization of the colonies should be avoided because it will reduce cell viability. This could occur by incubating cells too long with enzyme and/or over triturating. For one $10 \mathrm{~cm}$ plate of ESCs, $1 \mathrm{ml}$ of collagenase or trypsin solution was added and placed in incubator at $37^{\circ} \mathrm{C}$ for 5 to $10 \mathrm{~min}$. The plate was removed from the incubator, the bottom of the plate scraped with a $5 \mathrm{ml}$ pipette, making sure that all colonies had been lifted off, and then triturated slowly until only very small clumps were obtained. The colonies were not broken up into single cells as unlike their mouse counterparts, human ESCs do not survive well as single cells. The cell suspension was transferred into a $15 \mathrm{ml}$ conical tube, $10 \mathrm{ml}$ complete medium added and centrifuged for 5 to $10 \mathrm{~min}$ at $200 \mathrm{~g}$ at room temperature (RT). The pellet was resuspended in complete medium and placed onto mitotically-inactivated MEF feeder cell plate containing ESC complete medium with FGF2. The medium was replaced daily until ESC colonies reached optimal size for further passage. ESCs usually expanded by 5 fold after 5-7 days.

\subsubsection{Embryoid body formation}

Neural differentiation of ESCs was initiated via embryoid body (EB) suspensions. Embryonic stem cells were plated and dissociated onto $10 \mathrm{~cm}$ matrigel-coated tissue culture dishes as described above for passaging ESCs onto $10 \mathrm{~cm}$ plates with MEF. When ESCs were transferred onto matrigel they were grown in basic ESC culture media that had been conditioned on MEFs (live or irradiated) for 24 hours $(12 \mathrm{ml}$ of media per $10 \mathrm{~cm}$ of confluent feeders), filtered and supplemented with $4 \mathrm{ng} / \mathrm{ml}$ FGF2. MEF-conditioned media was replaced on a daily basis until colonies were large and tight, almost near confluency in the wells.

To generate embryoid bodies, the medium was removed from a culture dish of ESCs and the dish washed with PBS. For one six well plate of ESCs, the cells were incubated in $0.5 \mathrm{ml}$ 
of $1 \mathrm{mg} / \mathrm{ml}$ collagenase in PBS (avoid trypsinization as it can affect cell viability) and placed into the incubator at $37^{\circ} \mathrm{C}$ for 5 to $10 \mathrm{~min}$. After removing the tube from the incubator, the cells were scraped with a cell scraper or lifter. The cell suspension was transferred to a centrifuge tube very gently, $10 \mathrm{ml}$ of neural basal media supplemented with $200 \mathrm{ng} / \mathrm{ml}$ noggin, $20 \mathrm{ng} / \mathrm{ml} \mathrm{FGF2}$, and $20 \mathrm{ng} / \mathrm{ml} \mathrm{FGF4}$ (all growth factors from R\&D Systems) was added and centrifuged for $5 \mathrm{~min}$ at $200 \mathrm{~g}$, (RT). The supernatant was removed and the pellet gently resuspended into complete medium and placed onto a non-adherent or low adhesive $10 \mathrm{~cm}$ culture plate (Corning).

Neural EBs were fed daily by sedimentation. This was performed by tilting the dish at a 45 degree angle, waiting 5 minutes, and carefully aspirating with a $5 \mathrm{ml}$ pipette only half of the media so as to not discard the EBs floating in suspensions. EBs were grown for 10-25 days until they produced a transparent morphology. EBs were characterized by their loss of pluripotent markers, AP, OCT4, and NANOG and initiation of early markers of neuroectodermal fate including SSEA1, SOX1, PAX6 and Islet1 (Figure 1). The time may vary for different cell lines to reach this stage. Thus, the time at which is takes EBs to express these markers is dependent on the ESC line employed and so the cells should always be characterized at this point before proceeding forward. This can be performed by RT-PCR and by immunohistochemistry by freezing EBs in cryoprotectant mount media such as O.C.T. (Sakura Finetek TissueTek) and antibody staining (Table 1). The timeline provided here is based on our experiences using ESC lines H1 and H9 generated by Thomson et al (Thomson et al. 1998).

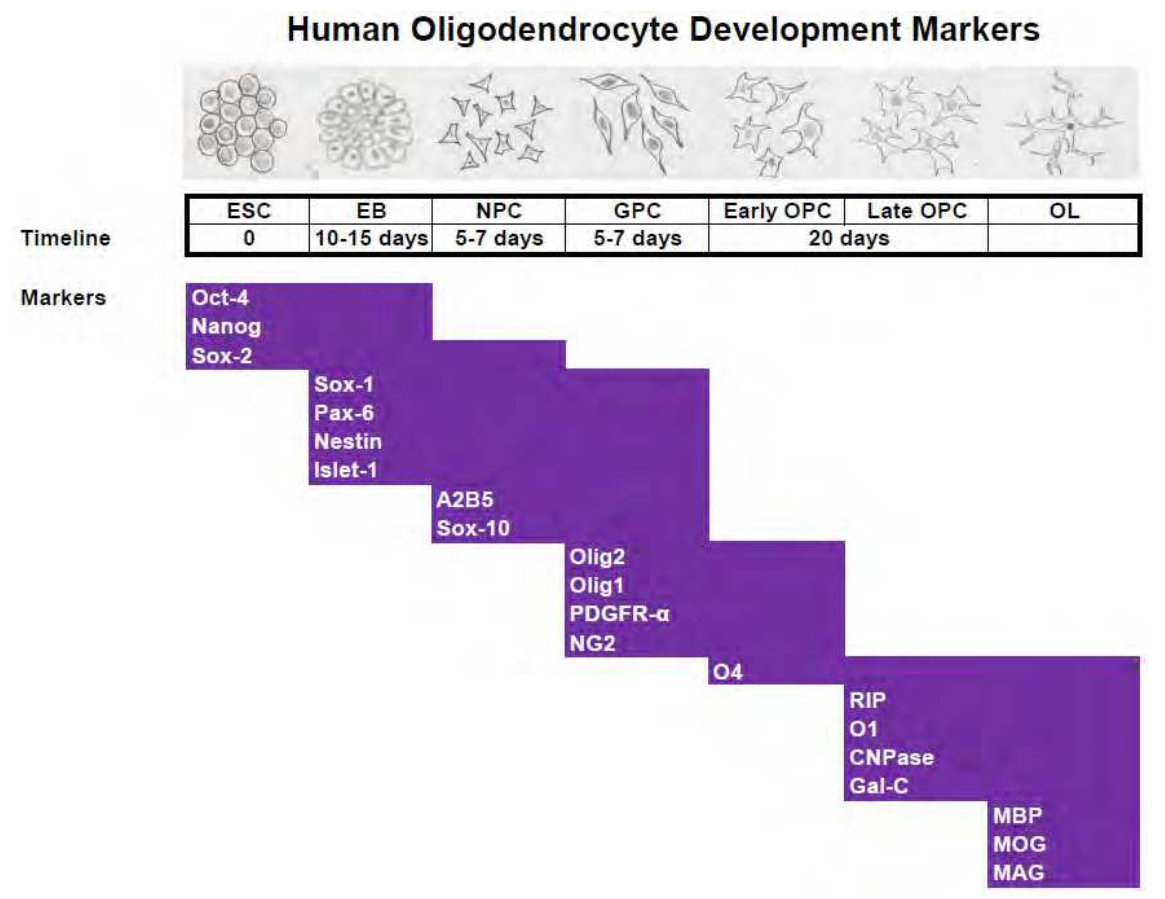

Fig. 1. Timeline of oligodendrocyte differentiation from pluripotent human embryonic stem cells, showing the expression of relevant cellular markers at each stage. 

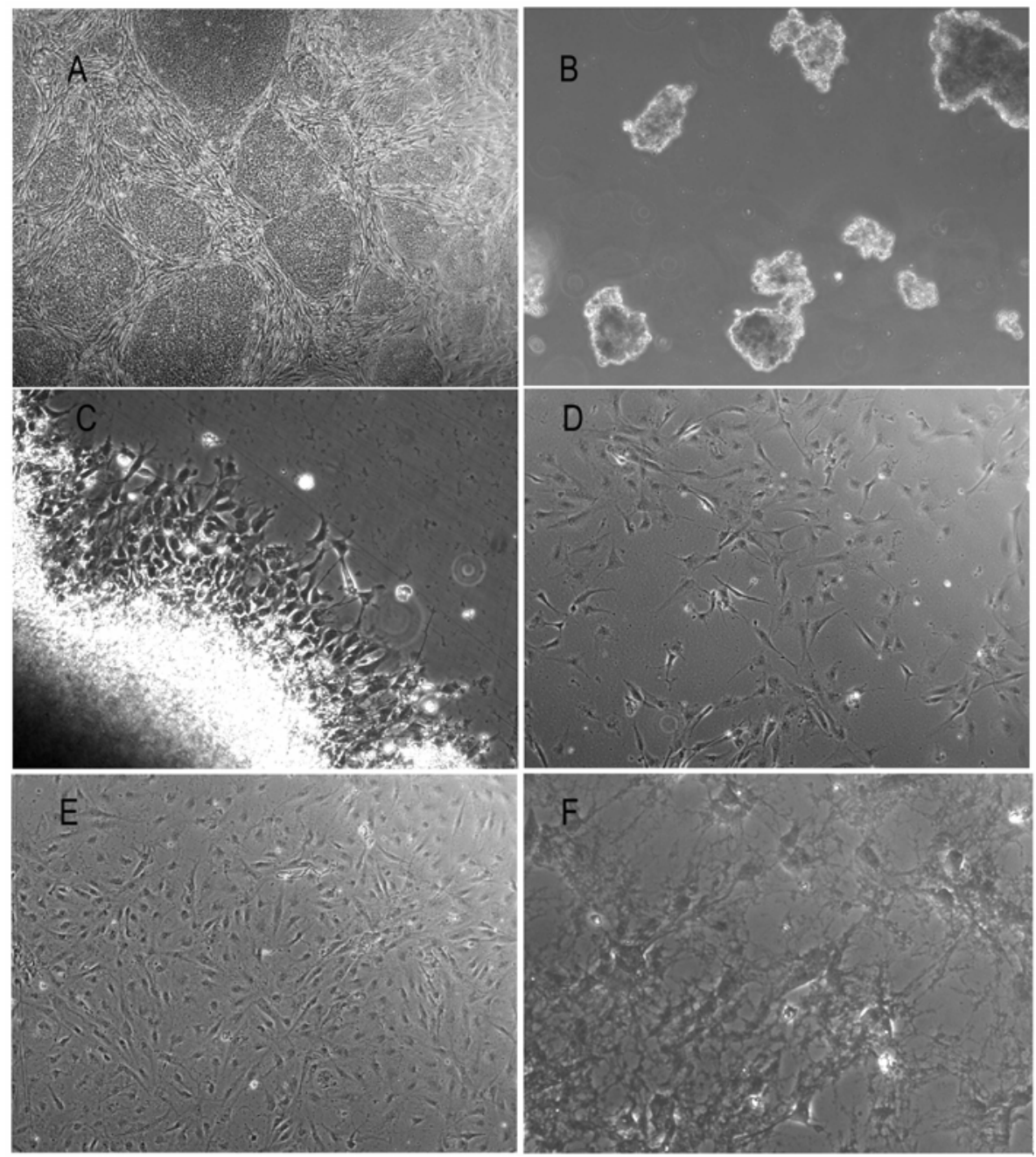

Fig. 2. Phase contrast images of various stages of oligodendrocyte differentiation.

A. Pluripotent human embryonic stem cells on MEFs, B. EBs one day after being generated by the scraping method, C. NPCs sprouting from the periphery of a plated EB on matrigel after 24 hrs, D. OPC 9 days after 2 expansions in OPC inducing medium, and OLs one week after being exposed to OL inducing media.

\subsubsection{Neural progenitor cells}

$10 \mathrm{~cm}$ tissue culture plates were coated with $3 \mathrm{ml}$ of $4 \%$ matrigel in neural basal media for one hour prior to plating EBs. Human ESC Qualified Matrigel Matrix was thawed overnight at $4^{\circ} \mathrm{C}$ then diluted 1:24 (approximately 4\% Matrigel) in cold neural basal medium. Afterwards, the matrigel was removed and EBs plated in $10 \mathrm{ml}$ of neural basal media supplemented with $20 \mathrm{ng} / \mathrm{ml} \mathrm{FGF2} \mathrm{for} 5$ to 10 days. In this time, EBs spread over the plate 
and became confluent. Most cells expressed neural fated markers including nestin and neural surface marker (A2B5) (Figure 1). NPCs at this stage were capable of deriving cells with both neuronal and glial fates. NPCs were fed daily.

\subsubsection{Glial progenitor cells}

NPCs were passaged in 1 to 3 splits for expansion using collagenase as described below (Passaging Cells) and replated on matrigel coated plates for differentiation into glial progenitor fate. Twenty-four hours after replating, media was changed to neural basal media supplemented with $20 \mathrm{ng} / \mathrm{ml}$ EGF. Cells were fed daily for 10-14 days. GPCs began to express NG2, PDGFRa, and Olig1 (Figure 1). These cells can differentiate into either astrocytes or oligodendrocytes at this stage depending on the growth factors employed.

\subsubsection{Oligodendrocyte progenitor cells}

To promote differentiation into OPC, the media was supplemented with $20 \mathrm{ng} / \mathrm{ml}$ PDGFAA. Cells were fed daily and begin to express OPC markers O1, O4, CNP, RIP, and GalC after one week (Figure 1). After 7-10 days the OPC morphology could be detected and was visible on the culture dish (Figure 2). By two weeks greater than $95 \%$ pure OPC could be obtained. Pure populations of OPCs can be obtained by FACs or MACs using O1 and O4 antibody selection using standard procedures. Once an OPC line is derived, cells can be expanded using $1 \mathrm{mg} / \mathrm{ml}$ collagenase in PBS onto gelatin-coated plates for several months before they reach senescence.

\subsubsection{Oligodendrocytes}

Terminal differentiation to mature oligodendrocytes was initiated by the addition of 50 $\mathrm{ng} / \mathrm{ml}$ T3 (triiodothyronine, Sigma) and removal of PDGF-AA from the neural basal medium. Mature OLs demonstrate complex morphology after 3-5 days and express myelinassociated proteins such as MAG, MOG, MOBP, and MBP (Figure 1). These cells do not survive as long as the progenitor cells and begin to die off after the first week. In total, their survival under these culture conditions is between 1-3 weeks after maturity.

\subsubsection{Passaging cells}

$3 \mathrm{ml}$ of $0.1 \%$ matrigel is placed on a $10 \mathrm{~cm}$ tissue culture plate. The medium is removed from a culture dish of OL-fated cells and the dish washed with PBS. For one six well plate, the cells were incubated in $0.5 \mathrm{ml}$ of $1 \mathrm{mg} / \mathrm{ml}$ collagenase in PBS (avoid trypsinization as it can affect cell viability) and cells placed into the incubator at $37^{\circ} \mathrm{C}$ for 5 to $10 \mathrm{~min}$. After removing the tube from the incubator, the cells were scraped with cell scraper or lifter. The suspension was mixed by gently pipetting up and down the cell clumps until a single-cell suspension was obtained. Importantly, to reduce cell mortality, the extent of cell disruption was controlled by pipetting only 5 to 10 times and with a $5 \mathrm{ml}$ pipette. The cell suspension was transferred to a centrifuge tube and centrifuge for $5 \mathrm{~min}$ at $200 \mathrm{~g}$ at RT. The supernatant was removed and pellet resuspended in complete medium and placed onto the matrigelcoated plates. Medium was replaced daily until the cells were confluent before passaging onto a larger culture dish plate.

\subsubsection{Freezing cells}

From one confluent 6-well ESCs, NPCs, GPCs or OPCs were dissociated using collagenase as described above. These were rinsed in neural basal media for neural cells and ESC media 
for ESCs at $200 \mathrm{~g}$ for $5 \mathrm{~min}$. The supernatant was aspirated and the pellet resuspended in freshly prepared 1X Freezing Media (for neural cells: 50\% Neural Basal Media, 40\% FCS, 10\% DMSO; ESC freezing media: 50\% Fetal Bovine Serum (Defined, Hyclone), 40\% Neural Basal Media (Invitrogen) and 10\% DMSO (Sigma), filtered). $1 \mathrm{ml}$ of freezing media was added dropwise, mixing well after each addition. The suspension was transferred into sterile freezing vials, and placed into cryovessels. The cells were frozen overnight at $-80^{\circ} \mathrm{C}$, and then transferred to the liquid nitrogen freezer after 24 hours.

\subsubsection{Thawing out cells}

The vial of frozen cells was removed from the nitrogen freezer and transferred to a $37^{\circ} \mathrm{C}$ heat water bath to thaw by gentle shaking (thawing generally takes only 1-2 minutes). The suspension was transferred into $15 \mathrm{cc}$ conical tube and $10 \mathrm{ml}$ of culture media added and centrifuged at $200 \mathrm{~g}$ for $5 \mathrm{~min}$. The supernatant was removed, culture medium added, and plated directly onto a fresh matrigel coated plate for NPs, GPCs and OPCs or feeder plate for ESCs.

\begin{tabular}{|l|l|l|}
\hline Name & Company & Product Code \\
\hline Oct-4 & BD Biosciences & 611203 \\
\hline Nanog & EBioscience & $14-5768-82$ \\
\hline Sox-2 & Abcam & ab15830-100 \\
\hline Sox-1 & Abcam & ab22572 \\
\hline Pax-6 & Abcam & ab5790 \\
\hline Nestin & Millipore & mab5326 \\
\hline Islet-1 & DSHB & $394 \mathrm{D} 5$ \\
\hline A2B5 & Millipore & mab312r \\
\hline Sox-10 & Santa Cruz Bio. & sc17343 \\
\hline Olig1 & Millipore & mab5540 \\
\hline PDGFR-a & Abcam & ab61219 \\
\hline NG2 & Millipore & ab5320 \\
\hline O4 & Millipore & mab345 \\
\hline O1 & Millipore & mab344 \\
\hline RIP & Abcam & ab2035 \\
\hline CNPase & Millipore & mab326r \\
\hline MBP & Abcam & ab7349-2 \\
\hline
\end{tabular}

Table 1. Specific antibodies for oligodendrocyte characterization

\subsection{Cell characterization}

The identity of a cell in the differentiation pathway from pluripotent embryonic stem cells to mature oligodendrocytes is most commonly studied by its morphology, its gene expression and by analyzing the expression of protein markers by immunodetection. 
Morphologically, undifferentiated ESCs generate colonies on top of feeders, NPC are more columnar or cuboidal in shape while GPCs and OPCs generate bipolar cells. Mature OLs demonstrate a complex network of dendritic processes (Figure 2).

Immunofluorescence (IF) staining of plated cells is more accurate morphology and the simplest method of analyzing protein expression to define the different stages of OL potential (Table 1 lists sources of reliable antibodies for OL characterization). Here we present a standard protocol for IF staining for OL fated cells. Figure 3 demonstrates staining at various stages of OL differentiation.

Cells were plated onto 24-well culture plates. Before cells became confluent, cells were washed twice in PBS and the excess PBS was removed. Cells were fixed in 4\% PFA in PBS for 10 minutes at RT. The fixative solution was removed and wells washed twice with PBS for $5 \mathrm{~min}$ each. Cells were permeabilized and blocked with PBS solution containing $0.2 \%$ $(\mathrm{w} / \mathrm{v})$ Triton X-100 and bovine serum albumin (BSA; Sigma) at a concentration $1 \%(\mathrm{w} / \mathrm{v})$ in PBS and incubated for 5 minutes at RT (for cells surface markers this step was skipped). Primary antibody (1:50 dilution) was added after dilution in antibody dilution buffer (PBS with $0.1 \%(\mathrm{w} / \mathrm{v}) \mathrm{BSA})$ and incubated for $1 \mathrm{hr}$ at RT. Sample was washed three times with PBS for 5 minutes each. Appropriate secondary antibody was added (Alexa488 or Alexa546 conjugated antibodies, 1:200; Molecular Probes) in antibody dilution buffer and incubated in a humidified dark chamber for $1 \mathrm{hr}$ at RT. Washed three times with PBS for 5 min each. Nuclei were stained with DAPI solution (Sigma) for $10 \mathrm{~min}$ at RT in a humidified chamber in the dark. DAPI solution was aspirated and $0.5 \mathrm{ml}$ PBS was added to each well. Samples were examined under a fluorescence microscope with appropriate filters within $24 \mathrm{hrs}$ as signal diminishes very rapidly. After 2 to 3 days most of the fluorescence signal is bleached. Sealant tape and aluminum foil was applied around the plates and stored in the dark at $4^{\circ} \mathrm{C}$ (short term storage only).

\section{Results}

\subsection{Morphological analysis of differentiated cells}

As shown in Figure 2, oligodendrocytes were successfully differentiated from human embryonic stem cells by our protocol described above. Embryoid bodies (Fig. 2b) were generated from pluripotent embryonic stem cells colonies (Fig. 2a). Plating these embryoid bodies on matrigel led to their adhesion and appearance of neural progenitor cells (Fig. 2c), which were then differentiated to glial progenitors (Fig. 2d) and subsequently oligodendrocyte progenitor cells (Fig 2e). Removal of all growth factors from the media led to the appearance of mature oligodendrocytes (Fig. 2e).

\subsection{Immunocytochemistry of differentiated cells}

EBs were characterized by their loss of pluripotent markers, AP, OCT4, and NANOG and initiation of early markers of neuroectodermal fate including SSEA1, SOX1, PAX6 and Islet1 (Figure 1). Upon contact with matrigel, EBs spread over the plate and became confluent. Most cells expressed neural fated markers including nestin and neural surface marker (A2B5)(Figure 1). After 5-7 days in NP media and addition of EGF, GPCs appeared and began to express NG2, PDGFRa, and Olig1 (Figure 1). Subsequent addition of PDGF-AA after 7 days led to the appearance of OPC markers O1, O4, CNP, RIP, and GalC (Figure 1). Finally, mature oligodendrocytes express myelin-associated proteins such as MAG, MOG, MOBP, and MBP (Figure 1). 
Immunofluorescent images for a few of these markers are shown in Figure 3.
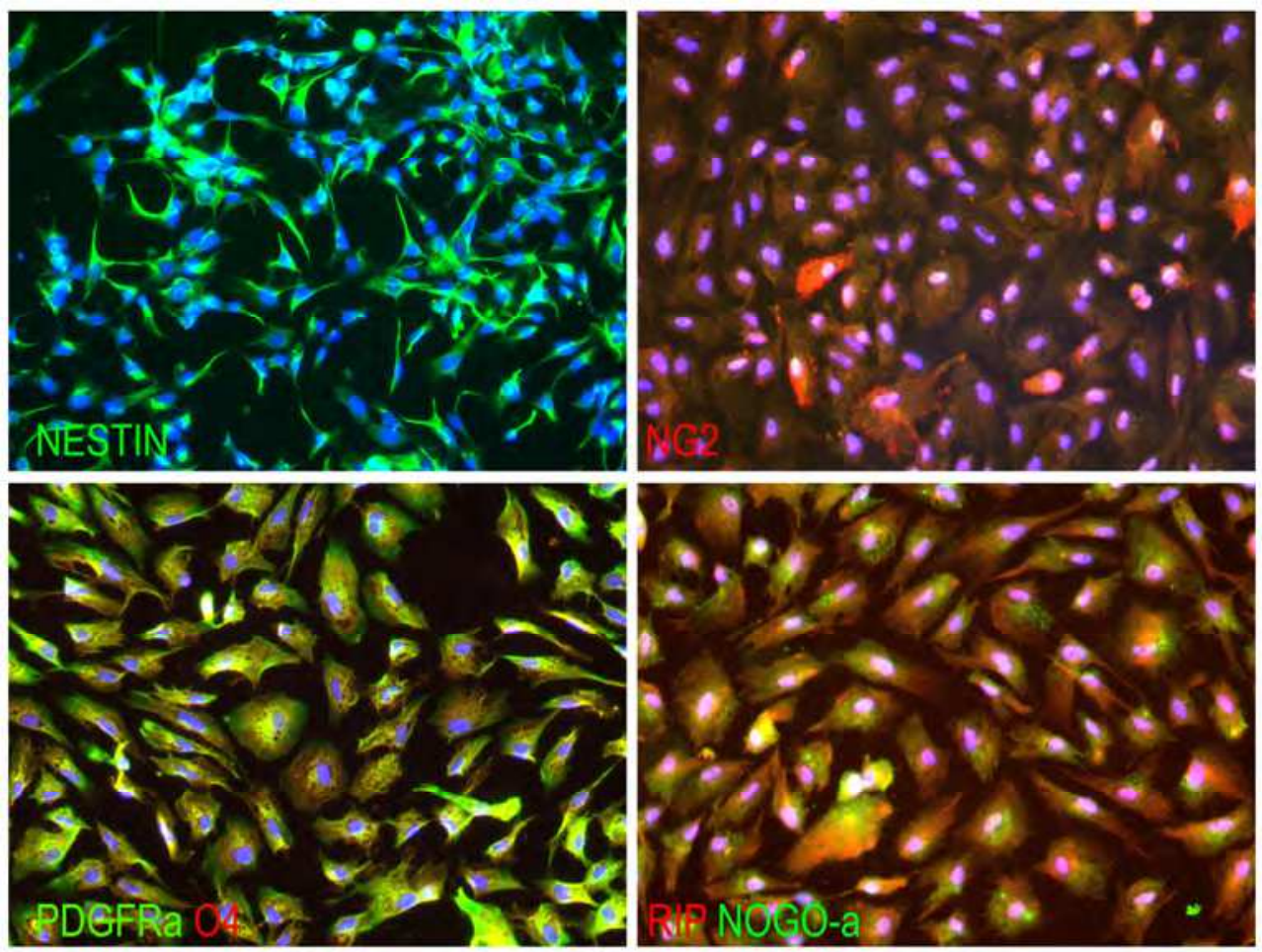

Fig. 3. Indirect immunofluorescence microscopy to examine differentiation of human ESCs into the oligodendrocyte lineage. The nuclei are stained blue by DAPI. Nestin (green) is shown for neural progenitors while NG2 (red), PDGFRa (green) O4 (red), RIP (red) and NOGO-a (green) are expressed by 5-day old oligodendrocyte progenitor cells.

\section{Conclusion}

In conclusion, a novel protocol adapted from previously published ones for oligodendrocyte development from pluripotent human embryonic stem cells has been developed. The cells express the established neural, glial and oligodendroglial markers as they advance along the differentiation timeline and we have confirmed this using indirect immunofluorescent microscopy.

Also, we have reviewed the current state of knowledge about microRNA regulation of oligodendrocyte differentiation from pluripotent cells and myelination of CNS neurons by those cells. It is hoped that the protocol for obtaining OLs in high purity will aid in the unraveling of more mechanisms of miRNA regulation of myelination so that this knowledge can eventually be used for the development of a more efficient approach to the stem cell based therapy of spinal cord injuries and other demyelinating disorders. 


\section{References}

Bentwich, I., Avniel, A., Karov, Y., Aharonov, R., Gilad, S., Barad, O., Barzilai, A., Einat, P., Einav, U. \& Meiri, E. 2005, "Identification of hundreds of conserved and nonconserved human microRNAs", Nature genetics, vol. 37, no. 7, pp. 766-770.

Berezikov, E., Guryev, V., van de Belt, J., Wienholds, E., Plasterk, R.H.A. \& Cuppen, E. 2005, "Phylogenetic shadowing and computational identification of human microRNA genes", Cell, vol. 120, no. 1, pp. 21-24.

Bernstein, E., Caudy, A.A., Hammond, S.M. \& Hannon, G.J. 2001, "Role for a bidentate ribonuclease in the initiation step of RNA interference", Nature, vol. 409, no. 6818, pp. 363-365.

Bernstein, E., Kim, S.Y., Carmell, M.A., Murchison, E.P., Alcorn, H., Li, M.Z., Mills, A.A., Elledge, S.J., Anderson, K.V. \& Hannon, G.J. 2003, "Dicer is essential for mouse development", Nature genetics, vol. 35, no. 3, pp. 215-217.

Besnard, F., Perraud, F., Sensenbrenner, M. \& Labourdette, G. 1987, "Platelet-derived growth factor is a mitogen for glial but not for neuronal rat brain cells in vitro", Neuroscience letters, vol. 73, no. 3, pp. 287-292.

Brennecke, J., Hipfner, D.R., Stark, A., Russell, R.B. \& Cohen, S.M. 2003, "bantam encodes a developmentally regulated microRNA that controls cell proliferation and regulates the proapoptotic gene hid in Drosophila", Cell, vol. 113, no. 1, pp. 25-36.

Carmell, M.A., Xuan, Z., Zhang, M.Q. \& Hannon, G.J. 2002, "The Argonaute family: tentacles that reach into RNAi, developmental control, stem cell maintenance, and tumorigenesis", Genes $\mathcal{E}$ development, vol. 16, no. 21, pp. 2733.

Chen, C., Ridzon, D., Lee, C.T., Blake, J., Sun, Y. \& Strauss, W.M. 2007, "Defining embryonic stem cell identity using differentiation-related microRNAs and their potential targets", Mammalian Genome, vol. 18, no. 5, pp. 316-327.

Cheng, A.M., Byrom, M.W., Shelton, J. \& Ford, L.P. 2005, "Antisense inhibition of human miRNAs and indications for an involvement of miRNA in cell growth and apoptosis", Nucleic acids research, vol. 33, no. 4, pp. 1290.

Draper, J.S., Moore, H.D., Ruban, L.N., Gokhale, P.J. \& Andrews, P.W. 2004, "Culture and characterization of human embryonic stem cells", Stem Cells and Development, vol. 13, no. 4, pp. 325-336.

Dugas, J.C., Cuellar, T.L., Scholze, A., Ason, B., Ibrahim, A., Emery, B., Zamanian, J.L., Foo, L.C., McManus, M.T. \& Barres, B.A. 2010, "Dicer1 and miR-219 are required for normal oligodendrocyte differentiation and myelination", Neuron, vol. 65, no. 5, pp. 597-611.

Dugas, J.C. \& Notterpek, L. 2011, "MicroRNAs in Oligodendrocyte and Schwann Cell Differentiation", Developmental neuroscience, .

Emery, B. 2010, "Regulation of oligodendrocyte differentiation and myelination", Science, vol. 330, no. 6005, pp. 779.

Emery, B., Agalliu, D., Cahoy, J.D., Watkins, T.A., Dugas, J.C., Mulinyawe, S.B., Ibrahim, A., Ligon, K.L., Rowitch, D.H. \& Barres, B.A. 2009, "Myelin gene regulatory factor is a critical transcriptional regulator required for CNS myelination", Cell, vol. 138, no. 1, pp. 172-185.

Grishok, A., Pasquinelli, A.E., Conte, D., Li, N., Parrish, S., Ha, I., Baillie, D.L., Fire, A., Ruvkun, G. \& Mello, C.C. 2001, "Genes and mechanisms related to RNA interference regulate expression of the small temporal RNAs that control C. elegans developmental timing", Cell, vol. 106, no. 1, pp. 23-34.

He, X., Yu, Y., Awatramani, R. \& Lu, Q.R. 2011, "Unwrapping Myelination by MicroRNAs", The Neuroscientist,. 
Hoffman, L.M. \& Carpenter, M.K. 2005, "Characterization and culture of human embryonic stem cells", Nature biotechnology, vol. 23, no. 6, pp. 699-708.

Hutvágner, G., McLachlan, J., Pasquinelli, A.E., Bálint, É., Tuschl, T. \& Zamore, P.D. 2001, "A cellular function for the RNA-interference enzyme Dicer in the maturation of the let-7 small temporal RNA", Science, vol. 293, no. 5531, pp. 834.

Hutvágner, G., Simard, M.J., Mello, C.C. \& Zamore, P.D. 2004, "Sequence-specific inhibition of small RNA function", PLoS Biology, vol. 2, no. 4, pp. e98.

Junker, A., Hohlfeld, R. \& Meinl, E. 2010, "The emerging role of microRNAs in multiple sclerosis", Nature Reviews Neurology, vol. 7, no. 1, pp. 56-59.

Junker, A., Krumbholz, M., Eisele, S., Mohan, H., Augstein, F., Bittner, R., Lassmann, H., Wekerle, H., Hohlfeld, R. \& Meinl, E. 2009, "MicroRNA profiling of multiple sclerosis lesions identifies modulators of the regulatory protein CD47", Brain, vol. 132, no. 12, pp. 3342.

Kerr, C.L., Letzen, B.S., Hill, C.M., Agrawal, G., Thakor, N.V., Sterneckert, J.L., Gearhart, J.D. \& All, A.H. 2010, "Efficient differentiation of human embryonic stem cells into oligodendrocyte progenitors for application in a rat contusion model of spinal cord injury", International Journal of Neuroscience, vol. 120, no. 4, pp. 305-313.

Ketting, R.F., Fischer, S.E.J., Bernstein, E., Sijen, T., Hannon, G.J. \& Plasterk, R.H.A. 2001, "Dicer functions in RNA interference and in synthesis of small RNA involved in developmental timing in C. elegans", Genes \& development, vol. 15, no. 20, pp. 2654.

Knight, S.W. \& Bass, B.L. 2001, "A role for the RNase III enzyme DCR-1 in RNA interference and germ line development in Caenorhabditis elegans", Science, vol. 293, no. 5538, pp. 2269.

Kondo, T. \& Raff, M. 2000, "Basic helix-loop-helix proteins and the timing of oligodendrocyte differentiation", Development, vol. 127, no. 14, pp. 2989.

Lagos-Quintana, M., Rauhut, R., Lendeckel, W. \& Tuschl, T. 2001, "Identification of novel genes coding for small expressed RNAs", Science, vol. 294, no. 5543, pp. 853.

Lau, P., Verrier, J.D., Nielsen, J.A., Johnson, K.R., Notterpek, L. \& Hudson, L.D. 2008, "Identification of dynamically regulated microRNA and mRNA networks in developing oligodendrocytes", Journal of Neuroscience, vol. 28, no. 45, pp. 11720.

Lee, R.C. \& Ambros, V. 2001, "An extensive class of small RNAs in Caenorhabditis elegans", Science, vol. 294, no. 5543, pp. 862.

Lee, R.C., Feinbaum, R.L. \& Ambros, V. 1993, "The C. elegans heterochronic gene lin-4 encodes small RNAs with antisense complementarity to lin-14", Cell, vol. 75, no. 5, pp. 843-854.

Lee, Y., Jeon, K., Lee, J.T., Kim, S. \& Kim, V.N. 2002, "MicroRNA maturation: stepwise processing and subcellular localization", The EMBO journal, vol. 21, no. 17, pp. 46634670.

Letzen, B.S., Liu, C., Thakor, N.V., Gearhart, J.D., All, A.H., Kerr, C.L. \& Linden, R. 2010, "MicroRNA expression profiling of oligodendrocyte differentiation from human embryonic stem cells", PLoS One, vol. 5, no. 5, pp. e10480.

Lin, S.T. \& Fu, Y.H. 2009, "miR-23 regulation of lamin B1 is crucial for oligodendrocyte development and myelination", Disease Models E Mechanisms, vol. 2, no. 3-4, pp. 178.

Liu, A., Li, J., Marin-Husstege, M., Kageyama, R., Fan, Y., Gelinas, C. \& Casaccia-Bonnefil, P. 2006, "A molecular insight of Hes5-dependent inhibition of myelin gene expression: old partners and new players", The EMBO journal, vol. 25, no. 20, pp. 4833-4842.

Lu, J., Hou, R., Booth, C.J., Yang, S.H. \& Snyder, M. 2006, "Defined culture conditions of human embryonic stem cells", National Acad Sciences, . 
Ludwig, T.E., Bergendahl, V., Levenstein, M.E., Yu, J., Probasco, M.D. \& Thomson, J.A. 2006, "Feeder-independent culture of human embryonic stem cells", Nature methods, vol. 3, no. 8, pp. 637-646.

Meister, G., Landthaler, M., Dorsett, Y. \& Tuschl, T. 2004, "Sequence-specific inhibition of microRNA-and siRNA-induced RNA silencing", Rna, vol. 10, no. 3, pp. 544.

Moreau, M.P., Bruse, S.E., David-Rus, R., Buyske, S. \& Brzustowicz, L.M. 2011, "Altered microRNA expression profiles in postmortem brain samples from individuals with schizophrenia and bipolar disorder", Biological psychiatry, vol. 69, no. 2, pp. 188-193.

Murchison, E.P., Partridge, J.F., Tam, O.H., Cheloufi, S. \& Hannon, G.J. 2005, "Characterization of Dicer-deficient murine embryonic stem cells", Proceedings of the National Academy of Sciences of the United States of America, vol. 102, no. 34, pp. 12135.

Nistor, G.I., Totoiu, M.O., Haque, N., Carpenter, M.K. \& Keirstead, H.S. 2005, "Human embryonic stem cells differentiate into oligodendrocytes in high purity and myelinate after spinal cord transplantation", Glia, vol. 49, no. 3, pp. 385-396.

Padiath, Q.S., Saigoh, K., Schiffmann, R., Asahara, H., Yamada, T., Koeppen, A., Hogan, K., Ptácek, L.J. \& Fu, Y.H. 2006, "Lamin B1 duplications cause autosomal dominant leukodystrophy", Nature genetics, vol. 38, no. 10, pp. 1114-1123.

Park, J.H., Kim, S.J., Oh, E.J., Moon, S.Y., Roh, S.I., Kim, C.G. \& Yoon, H.S. 2003, "Establishment and maintenance of human embryonic stem cells on STO, a permanently growing cell line", Biology of reproduction, vol. 69, no. 6, pp. 2007.

Pillai, R.S., Bhattacharyya, S.N. \& Filipowicz, W. 2007, "Repression of protein synthesis by miRNAs: how many mechanisms?", Trends in cell biology, vol. 17, no. 3, pp. 118-126.

Qian, J., Zhai, A., Kao, W., Li, Y., Song, W., Fu, Y., Chen, X., Zhang, Q., Wu, J. \& Li, H. 2010, "Modulation of miR-122 on persistently Borna disease virus infected human oligodendroglial cells", Antiviral Research, vol. 87, no. 2, pp. 249-256.

Santarelli, D.M., Beveridge, N.J., Tooney, P.A. \& Cairns, M.J. 2011, "Upregulation of Dicer and MicroRNA Expression in the Dorsolateral Prefrontal Cortex Brodmann Area 46 in Schizophrenia", Biological psychiatry, vol. 69, no. 2, pp. 180-187.

Shin, D., Shin, J.Y., McManus, M.T., Ptcek, L.J. \& Fu, Y.H. 2009, "Dicer ablation in oligodendrocytes provokes neuronal impairment in mice", Annals of Neurology, vol. 66, no. 6, pp. 843-857.

Suemori, H., Yasuchika, K., Hasegawa, K., Fujioka, T., Tsuneyoshi, N. \& Nakatsuji, N. 2006, "Efficient establishment of human embryonic stem cell lines and long-term maintenance with stable karyotype by enzymatic bulk passage", Biochemical and biophysical research communications, vol. 345, no. 3, pp. 926-932.

Thomson, J.A., Itskovitz-Eldor, J., Shapiro, S.S., Waknitz, M.A., Swiergiel, J.J., Marshall, V.S. \& Jones, J.M. 1998, "Embryonic stem cell lines derived from human blastocysts", Science, vol. 282, no. 5391, pp. 1145.

VandeWoude, S., Richt, J.A., Zink, M.C., Rott, R., Narayan, O. \& Clements, J.E. 1990, "A Borna virus cDNA encoding a protein recognized by antibodies in humans with behavioral diseases", Science, vol. 250, no. 4985, pp. 1278.

Wightman, B., Ha, I. \& Ruvkun, G. 1993, "Posttranscriptional regulation of the heterochronic gene lin-14 by lin-4 mediates temporal pattern formation in C. elegans", Cell, vol. 75 , no. 5 , pp. 855-862.

Xu, B., Karayiorgou, M. \& Gogos, J.A. 2010, "MicroRNAs in psychiatric and neurodevelopmental disorders", Brain research, vol. 1338, pp. 78-88.

Zheng, K., Li, H., Zhu, Y., Zhu, Q. \& Qiu, M. 2010, "MicroRNAs Are Essential for the Developmental Switch from Neurogenesis to Gliogenesis in the Developing Spinal Cord", Journal of Neuroscience, vol. 30, no. 24, pp. 8245. 


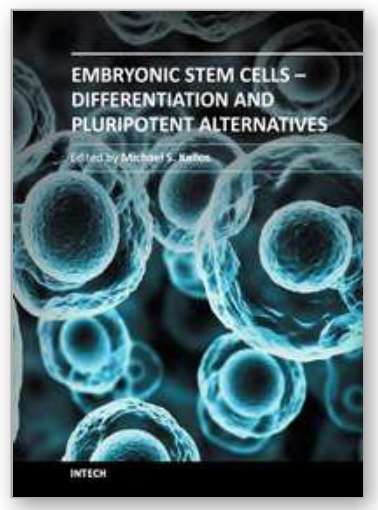

\author{
Embryonic Stem Cells - Differentiation and Pluripotent Alternatives \\ Edited by Prof. Michael S. Kallos
}

ISBN 978-953-307-632-4

Hard cover, 506 pages

Publisher InTech

Published online 12, October, 2011

Published in print edition October, 2011

The ultimate clinical implementation of embryonic stem cells will require methods and protocols to turn these unspecialized cells into the fully functioning cell types found in a wide variety of tissues and organs. In order to achieve this, it is necessary to clearly understand the signals and cues that direct embryonic stem cell differentiation. This book provides a snapshot of current research on the differentiation of embryonic stem cells to a wide variety of cell types, including neural, cardiac, endothelial, osteogenic, and hepatic cells. In addition, induced pluripotent stem cells and other pluripotent stem cell sources are described. The book will serve as a valuable resource for engineers, scientists, and clinicians as well as students in a wide range of disciplines.

\title{
How to reference
}

In order to correctly reference this scholarly work, feel free to copy and paste the following:

Siddharth Gupta, Angelo All and Candace Kerr (2011). Oligodendrocyte Fate Determination in Human Embryonic Stem Cells, Embryonic Stem Cells - Differentiation and Pluripotent Alternatives, Prof. Michael S. Kallos (Ed.), ISBN: 978-953-307-632-4, InTech, Available from: http://www.intechopen.com/books/embryonicstem-cells-differentiation-and-pluripotent-alternatives/oligodendrocyte-fate-determination-in-humanembryonic-stem-cells

\section{INTECH}

open science | open minds

\section{InTech Europe}

University Campus STeP Ri

Slavka Krautzeka 83/A

51000 Rijeka, Croatia

Phone: +385 (51) 770447

Fax: +385 (51) 686166

www.intechopen.com

\section{InTech China}

Unit 405, Office Block, Hotel Equatorial Shanghai

No.65, Yan An Road (West), Shanghai, 200040, China

中国上海市延安西路65号上海国际贵都大饭店办公楼405单元

Phone: +86-21-62489820

Fax: +86-21-62489821 
(C) 2011 The Author(s). Licensee IntechOpen. This is an open access article distributed under the terms of the Creative Commons Attribution 3.0 License, which permits unrestricted use, distribution, and reproduction in any medium, provided the original work is properly cited. 